\title{
Ultraviolet Radiation Exposure: Some Observations and Considerations, Focusing on Some Italian Experiences, on Cancer Risk, and Primary Prevention
}

\section{Lucia Miligi}

Environmental and Occupational Epidemiology Branch-Cancer Risk Factors and Lifestyle Epidemiology Unit, Institute for Cancer Research, Prevention and Clinical Network (ISPRO), Via Cosimo il Vecchio 2, 50139 Florence, Italy; 1.miligi@ispro.toscana.it

Received: 21 October 2019; Accepted: 19 January 2020; Published: 22 January 2020

check for updates

\begin{abstract}
Solar ultraviolet radiation may cause acute and chronic health effects on the skin, eyes, and also on the immune system. Actinic keratosis, non-melanoma skin cancers, and malignant melanoma are the main long-term adverse skin effects. In the white population, the most common type of cancer worldwide is skin cancer, and the incidence of this cancer has increased during the last decades. The most important risk factor responsible for this trend seems to be Ultraviolet Radiation (UVR). IARC has classified UVR as being carcinogenic to humans. UV radiation exposure is ubiquitous; to study skin cancer risk, it is important to take into account the fact that UV exposure may occur both for occupational activities but also during vacation or recreational activities. Furthermore, exposure to artificial UVR such as those emitted by artificial devices, classified by IARC as carcinogenic to humans, is also to be considered. Due to the prominent role of UVR, primary prevention of skin cancer is very suitable, because when following specific rules this risk factor can be reduced. The incidence rate of skin cancer is higher in people with fair skin. Outdoor workers exposed to solar UVR are at risk of developing skin cancer, particularly non-melanoma skin cancers, and welders exposed to artificial UVR are at risk of developing ocular melanoma. A specific project on solar UVR risk in outdoor workers in Tuscany, Italy, has shown that outdoor workers had an unsatisfactory sun protection behaviour. The project demonstrates the complexity of studying UVR exposure and recommended the need for prevention programs. Risk increases with increasing ambient solar radiation and with unsafe behaviours in the sun or when using artificial UVR (e.g., sunbeds). Effective prevention strategies have to be adopted both for the outdoor workers and for the general population exposed to UVR. A standardized program of proven efficacy, such as that implemented in Australia, should also be implemented in other countries. All these strategies could contribute to the aim of decreasing the morbidity and mortality of cancers associated with this exposure. The aim of this paper is to provide an overview of UVR exposure risk, particularly occupational risk, and to give some elements to understand the complexity of the relation between UVR exposure and cancer risk, as well as to outline primary prevention measures, focusing also on Italian experiences that could be useful for providing additional elements of knowledge on this topic.
\end{abstract}

Keywords: solar ultraviolet radiation; outdoor workers; UV tanning devices; primary prevention; skin cancer

\section{Introduction}

Epidemiological and laboratory studies have shown that UVR causes acute and chronic health effects on the skin, eyes, and also on the immune system. Sunburns and photodermatosis are the main acute effects, whereas photoaging, actinic keratosis (AK), and skin cancer are long-term effects of exposure to solar UVR exposure. The acute effects upon exposure to solar UVR on the eyes include 
photokeratitis and photoconjuntivitis, long-term effects on the pterygium, and also squamous cell carcinoma of the cornea and conjunctiva. Chronic exposure to solar UVR also contributes to cataracts, in particular cortical cataracts [1].

Sunlight has been known as an important cause of skin cancer since around the turn of the 20th century. In fact, by 1927 (for basal cell carcinoma (BCC) and squamous cell carcinoma (SCC)), and by 1955 (for melanoma), the relation between sun exposure and skin cancer had been established, and it has been observed that these cancers are more frequent in high-ambient solar irradiance areas, in sun-sensitive people, and that they occur mainly on sun-exposed body sites [2,3]. Furthermore, people with a high sun exposure are at a higher risk. The past 70 years have added both quantity and quality to the epidemiological evidence, supporting the role of UVR exposure in increasing skin cancer $[4,5]$.

The International Agency for Cancer Research (IARC) evaluated the carcinogenicity of UVR exposure on the base of the scientifically available evidence at the time of the review. Solar UVR was classified by the IARC as a carcinogenic for humans (Group 1) as early as in 1992 [6], and this assessment was confirmed in the monograph $100 \mathrm{D}$ published in 2012 [7]. The conclusive evaluation of the IARC is that there is sufficient evidence of the carcinogenicity of solar radiation in humans. Solar UVR causes cutaneous malignant melanoma (MM) and non-melanoma skin cancers (NMSC): SCC and BCC. The IARC also notes that there is a positive association, even if with limited evidence, with lip cancer, conjunctival squamous cell carcinoma, and eye melanoma, particularly in the choroid and the ciliary body. There is also sufficient evidence in animal experiments for the carcinogenicity of solar radiation in the broad UVR spectrum: UVA, UVB, and UVC radiation. There is sufficient evidence in humans for the carcinogenicity of the use of UV-emitting tanning devices (Group 1). UV-emitting tanning devices cause MM and ocular melanoma (observed in the choroid and the ciliary body of the eye). A positive association has been observed between the use of UV-emitting tanning devices and SCC of the skin [7].

The aim of this paper is to provide an overview of UVR exposure risk, particularly occupational risk, and to give some elements for understanding the complexity of this exposure and the cancer risk, as well as to outline primary prevention measures, focusing also on Italian experiences that could be useful for providing additional elements of knowledge on this topic.

\section{Burden of Skin Cancer}

Over the past fifty years, the incidence of MM and NMSC, especially in light-skinned populations, has increased steeply. The highest incidence rates are those observed in Australia and New Zealand, where a population with very fair skin is exposed to a high UVR [8,9]. Considering the GLOBOCAN (GLOBOCAN is the project of the IARC that provides estimates by cancer site and sex using the best available data in each country and several methods of estimation) data, in 2018 about 287,723 new diagnoses were expected in the world of MM, and 1,042,059 in the world of NMSC [10]. In Europe, incidence rates are particularly high in the Nordic countries, Switzerland, the Netherlands, the Czech Republic, and Slovenia, while lower rates were observed in the Mediterranean area, as well as in the Baltic and eastern areas. The incidence rates continue to rise in many European populations, and the prediction suggests a continuation of the rising trend [8].

The highest national rates of NMSC were observed in Australia/New Zealand (the age standardized rate per 100,00 (ASR) (The incidence is the number of new cases occurring in a specified period and geographic area, conveyed either as an absolute number of cases per annum or as a rate per 100,000 persons per year. The age-standardized rates (ASRs) per 100,000 person-years are calculated using the direct method and the world standard population) is 229.2, followed by Northern America (ASR $=76.9$ ), Western Europe (ASR = 34.1), Northern Europe (ASR = 28.8), Southern Africa (ASR = 16.4), and Southern Europe (ASR = 16.2). In females, the rates are lower than in males [10].

In 2018 in Italy, about 13,700 new cases of skin melanoma are expected, 7200 among men and 6500 among women ( $4 \%$ of all cancers in both sexes), and melanoma accounts for $9 \%$ of cancers in men aged 0-49 years (second most frequent neoplasm); and in women, in the same age class, it represents $7 \%$ of 
cancers (third most frequent neoplasm) [11]. In 2015, there were 1943 deaths from cutaneous melanoma (1136 men and 807 women) in Italy, equal to 1\% of deaths from cancer in both sexes, with a slightly higher frequency in the young age groups of the population, both male (4\%) and female (3\%) [11].

The incidence and time trends for NMSCs are more difficult to estimate, as they are often either not registered at all or not completely covered by population-based cancer registries [11]. Given their biological and clinical peculiarities, the high number, and good prognoses, some Cancer Registries do not collect them or limit themselves to the squamous cell forms, and AK is considered by some to be in situ SCC. For these reasons, their incidence is often neglected in the registers' cancer reports, even internationally. NMSC represent the most commonly diagnosed cancers; by far the most frequent forms are BCC, which have a good prognosis, while the incidence of SCC is lower, with a greater aggressiveness, at least locally. They are cancers that appear mainly in adulthood, in both sexes, but with a higher frequency among men [11]. From the Italian Cancer Registry data, it is estimated that in 2018 about 83,000 new cases will be diagnosed (about 64,000 BCC and 19,000 SCC); 48,000 in males and 35,000 in females) [11]. The incidence of these lesions increases significantly after 50 years of age for basal cell forms and 65 years for squamous cells. The mortality from these lesions is very rare, due to the poor metastatic potential, which is however largely reserved for the squamous-cell forms: in the literature, it is reported in less than $2 \%$ of these patients [11]. The onset of these skin carcinomas is also indicative of a series of carcinogenic exposures in susceptible subjects and is therefore associated both with the development of other secondary cancers of the same type and of different cancers [11]. This is the reason for the need to study in a more in-depth way the epidemiology of these cancers due to the possibility of an increased risk of developing cancer in other organs [11]. The preliminary data of Italian cancer registries show an excess risk of cancer in other organs that is equal to 20-25\%, with the results being consistent with those reported in the literature [11].

Whilst NMSC represent the most frequent type of cutaneous cancer and contribute to the rising morbidity as well as to a significant economic burden to health services, the mortality has remained consistently low [12,13].

The fourth edition of the European Code Against Cancer has dealt specifically with solar UVR radiation, and, in view of the fact that skin cancers are increasing worldwide and that UVR exposure is the main cause, effective protection measures must be adopted. The recommendation of the European Code Against Cancer is: "Avoid too much sun, especially for children. Use sun protections and avoid the use of artificial tanning devices [14]". This recommendation has been based on the epidemiological evidence and well known causal mechanisms, but also on the incidence increase of skin cancer, particularly in fair-skinned European populations, and on the observation that the principal risk factor, UVR exposure, may be modified by individual actions, taking also into account the beneficial effects of sunlight (e.g., vitamin D production) [14]. The most common cancer in fair-skinned populations is skin cancer, and among all skin cancers types MM represents about 5-10\%, whereas among NMSC BCC represents approximately $80-85 \%$ and SCC 15-20\% [14].

UVR is the main risk factor for the three main types of skin cancer confirmed by epidemiological and experimental studies; a sensitivity to UVR (sensitive skin type) represents the other most important risk factor related to skin cancers. The results from descriptive epidemiological and case-control studies provided most of the evidence for a causal relationship between solar UVR and MM. Large meta-analyses have shown that the principal risk factors for MM are also associated with UVR (the number of acquired nevi that are UV-induced, number of atypical nevi, sunburn, intermittent sun exposure, presence of actinic tumours, and total sun exposure) [14].

\section{Solar UVR Exposure and Outdoor Workers}

During their working life, outdoor workers may be exposed to high levels of solar UVR. The international information system on occupational exposures to certain or suspected carcinogens, CAREX (CAREX: International information system on occupational exposure to carcinogens in the European Union), points out that solar radiation is the most common occupational exposure in the 
European Community, estimating that about 9 million workers are exposed to solar radiation for at least $75 \%$ of their work time. In Italy, about 700,000 workers can be exposed to this carcinogen [15].

NMSC, particularly SCC, is the type of skin cancer that is most associated with outdoor work. Epidemiological studies and meta-analyses on NMSC risk and outdoor work have shown excesses of risk for these workers [16]. An increased risk of NMSC was observed in different outdoor professions such as farmers and fishermen, but gardeners and mountain guides may also be at a higher risk [17-19].

Two specific reviews and meta-analyses, published in 2011, show an overall statistically significant OR of 1.77 for SCC (95\% confidence interval [CI] 1.40-2.22) and an overall statistically significant OR of 1.43 for BCC $(95 \%$ CI 1.23-1.66) [20,21]. Outdoor workers are particularly at risk of being exposed to solar UVR during their work, especially when they work without adequate protections or by adopting behaviours that increase their risk, such as eating lunch outdoors [22]. NMSC is the skin cancer most associated with outdoor work, but some epidemiological studies also observed an increasing risk for MM. A recent European multicentre case control study, whose main objective was to compare the risk for BCC, SCC, MM, and AK in outdoor workers and in indoor workers, highlighted increases in risk for BCC and SCC, especially for workers in agriculture and the construction sectors, but the risk of all types of skin cancer, including $\mathrm{MM}$, and also $\mathrm{AK}$, was significantly increased for workers with $\geq 5$ years of outdoor work [23]. In some studies, it has been observed that the adoption of correct behaviours—e.g., wearing a hat or not eating lunch outside-reduces exposure [24,25]. Having a meal break in a shaded environment may reduce exposure due to the ambient UV being at its highest just after $12 \mathrm{pm}$ [25].

\subsection{A Specific Project in Italy on Solar UVR Risk in Outdoor Workers}

The risk of solar UVR exposure in outdoor workers may be reduced or avoided, and primary prevention programs can be implemented. In the Tuscany region, Italy, a specific project on solar UVR risk in outdoor workers [26] has been conducted, whose specific aims were:

(1) to study the sun protection attitude of outdoor workers in the construction, agriculture, fishing, and marble quarrying productive sectors;

(2) to carry out measurements of solar UVR in work environments;

(3) to report the frequency of photoaging, precancerous lesions, and skin cancers in outdoor workers of the productive sectors involved in the project;

(4) to study the NMSC cases recruited from the Tuscany Cancer Registry by collecting information, particularly on solar UVR exposure.

Outdoor workers filled a questionnaire to collect information on sun protection attitudes during a typical summer working week. Environmental and personal measurements were also carried out. Outdoor workers were examined by dermatologists who assessed the frequency of photoaging, precancerous lesions, and skin cancers. A structured questionnaire was mailed to incident cases of NMSC, collecting information on personal habits and working history, focusing on solar ultraviolet radiation exposure.

Agriculture, construction, marble quarrying, and fishing activities were considered in the project: 292 employees answered questions about the type of clothing used in the morning and in the afternoon while working outdoors; 637 outdoor workers underwent a skin examination. 498 out of 743 NMSC cases, recruited in 2004 from the Tuscany Cancer Registry, accepted to participate in this study. The study observed that outdoor workers wore clothing that was often inadequate compared to the high level of exposure to UV. The results of the skin examination of 637 outdoor workers showed that these workers presented both premature photo-aging of NMSC and AK (2 MM, 7 NMSC—also in dark phototypes-and $35 \mathrm{AK})$.

From the Tuscany Cancer Registry, among the 498 cases of NMSC, 135 (27\%) were diagnosed in outdoor workers, and the most represented economic activity sectors were: agriculture, construction, transport, and sports [26]. Personal and environmental measurements carried out in the Tuscany project have shown that outdoor work environments are characterized by high or very high personal 
dose values of biologically effective UV solar radiation [26]. It was noted that agriculture workers were exposed to high doses of solar UV radiation as early as April. In fishing, the data indicate the exposure of these workers to high doses of ultraviolet solar radiation as early as March. The doses of solar UVR absorbed by the photoexposed surfaces of fishermen vary according to the type of vessel and the availability of tents and shaded areas of work. Considering the environmental exposure, the albedo of marble was around 40-50\%, while that of cement was about $20 \%$ [26].

The Tuscany project had shown that outdoor workers revealed unsatisfactory sun protection behaviours; moreover, previously undetected skin cancers were also diagnosed in subjects with dark phototypes. The part of the study on MNSC cases confirms the complexity of studying UV radiation exposure and the need to also evaluate, in addition to occupational exposure, the recreational aspects and the use of tanning devices that can create an exposure to an additional dose of UVR. The Tuscany Regional project provided useful information on the risk of solar ultraviolet radiation in outdoor workers and suggested the need for prevention programs [26].

\subsection{Risk Assessment for Dermal and Ocular Exposure A New Tool}

In Italy, "The Physical Agents Portal (PAF)" has been realised by the Physical Agents Laboratory of the "USL Area Vasta Sud Est, Siena" in the frame of the "Targeted Plan for Risks Arising from Physical Agents", approved by the Tuscany Region Committee and in collaboration with Italian Workers' Compensation Authority (INAIL-Istituto Nazionale per 1'Assicurazione contro gli Infortuni sul Lavoro) and "Local Health Unit of Modena". The aim of the portal is to support risk assessment and prevention interventions in all working sectors exposed to physical agents and to provide an information tool that could support Security Managers and Prevention Operators in physical agents prevention and protection. For each single physical agent, there is a "Guide for Using the Database", and among the agents the exposure to UVR is also considered.

On the basis of ICNIRP document 14/2007 "Protecting Workers from Ultraviolet Radiation" [27], and with the aim of evaluating and preventing the work risk resulting from exposure to solar UVR in outdoor work, it is possible to carry out a quantitative risk assessment of dermal and ocular exposure for workers and to adopt the appropriate protective measures, in relation to the exposure mode and the environmental conditions of the exposure. A guided procedure that allows for the evaluation of the ICNIRP 14/2007 risk assessment criteria for sun exposure to the eyes and skin is available online on (PAF) (http://portaleagentifisici.it/fo_ro_naturali_calcolo_esposizione.php?lg=IT). The risk calculator for assessing the UVR risk on the skin and eyes of workers is an algorithm based on the following factors at work, which may increase the risk: latitude, presence or absence of clouds, work characteristics (exposure duration: all day, one or two hours of work between 12:00 and 16:00, work exposure before 10:00 and after 17:00), reflectance of the soil, type of clothing used during work, and presence or absence of shade. For each factor, a weight was established. The risk assessment evaluation was also based on the results of the Tuscany project.

\subsection{The Need to Recognize NMSCs from Exposure to Solar UVR as Occupational Cancers}

An article published in 2016 [28] points out that NMSCs are very frequent cancers in humans, and that their incidence is increasing and may be attributed to excessive exposure to UVR that characterized outdoor work. It is necessary to make specific actions at the international, European and national levels to recognize NCSC (and also AK) as an occupational disease [28]. In Italy, NMSC and $\mathrm{AK}$ are included in the list of occupational diseases that can be compensated in workers exposed to UVR by INAIL, while MM is not included in that list.

Considering the increase in the incidence of skin cancers, we should expect a high number of occupational skin cancers to be reported to the national workers' compensation authorities each year; nevertheless, a study examining the data of NMSC and AK by INAIL from 2012 to 2017 observed that occupational skin cancers in Italy are largely underreported [29]. The study clearly shows that urgent 
initiatives should be taken to raise appropriate awareness of the problem of occupational UVR-induced skin cancers, so that adequate preventive measures can be rapidly implemented [29].

\subsection{Workers Exposed to Artifical UV}

Welding is an occupation employing an estimated 11 million people worldwide, and welders are known to be exposed to UVR from the welding arc and often experience burns and localized cutaneous erythema. In 2017, UVR from welding was classified by IARC as carcinogenic to humans based on sufficient evidence of ocular melanoma in humans [30]. It has been hypothesized that exposure to UVR from the welding arc may also increase the risk of skin cancer among workers in this occupation [31].

\subsection{Prevention of Solar UVR Exposure Risk in Outdoor Workers}

Studying the exposure to solar UVR and the risk that is associated is complex, because people who have particular somatic characteristics are at a greater risk, particularly fair phototypes subjects; therefore, in the evaluation of the exposure to solar UV radiation in a working environment, individual factors must also be taken into account. Subjects who had a familiar history of MM, personal history of NMSC, or an immunosuppression or use of photosensitiser drugs [32] may be at a higher risk.

A comprehensive sun protection program should include measures that reduce exposure to UVR [33] by:

- $\quad$ physical changes in the work environment providing shade naturally (e.g., trees) or artificially $\overline{\text { from permanent }}$ or portable structures, or modifying reflective surfaces and using tinting on vehicles, as this can reduce the direct or indirect source of solar UVR.

- $\quad$ administrative controls that reduce UVR via a change in the work procedures and the way in which the work is organized, e.g., planning the work when the levels of solar UVR are lower (early in the morning or later in the afternoon), while during the hours of the day with a more intense UV (central hours of the day), inside work is privileged; additionally, ensuring that the lunch break takes place indoors or in shady places.

- $\quad$ personal protective equipment and clothing, including sun protective work clothing, sun protective hats, sunglasses, and (where possible) also sunscreen.

Protective clothing may offer different protection, in view of colour, closeness of weave, and condition, which can affect the ability of material to absorb solar UVR.

In fact, the safest protection from UVR exposure is offered by clothing, and its protectiveness depends on the fabric composition (natural, artificial, or synthetic fibres), fabric parameters (porosity, weight, and thickness) and dyeing (natural or synthetic dyes, dye concentration, UV absorbing properties, etc.). Grifoni et al [34] investigated the UV protection properties of two fabrics made of natural fibres (flax and hemp), dyed with some of the most common natural dyes. In the study, transmittance measurements were used to calculate the ultraviolet protection factor (UPF). The study results revealed that natural dyes could confer a good UVR protection, depending mainly on their different UVR-absorbing properties and provided that the fabric construction already guaranteed a good cover. An increase in the cover factor caused by the dyeing process was also detected. Weld-dyed (natural dye Reseda luteola L.) fabrics gave the highest protection level [34].

Clothing with a certified UPF, as with sunscreens, indicates the degree of protection against solar risk.

It is very important to use suitable hats that protect the ears, nose, and neck. A broad-brimmed hat or a legionnaire style hat provide the best protection.

Sunglasses must meet the standard requirements with regards to the filtering power of the lenses and the shape. Sunscreen should also be used with the other sun protection measures. Sunscreens have demonstrated their validity in reducing the incidence of both skin cancer and photoaging, but given the possibility of photoallergic and phototoxic effects associated with simultaneous exposure to chemical substances (e.g., pesticides) [35] or parts of plants (e.g., oil of bergamot, Umbelliferæ, etc.), their use in 
the work environment must include the involvement of occupational physicians. Workers must be educated on the correct use of sunscreen.

\section{Recreational Sun Exposure and Cancer Risk}

UVR may vary greatly within a person and between persons, depending on the specific geographical location, time of day and season, clothing and behaviour habits, and skin pigmentation.

Some people are at higher risk of skin cancers because they have a skin type that is more sensitive to UV damage (fair types) and may have an increased risk, particularly of MM, compared to people with darker types.

Several systematic reviews and meta-analyses from epidemiological studies focusing on the association of melanoma to sun exposure have been published [7]. A meta-analysis summarising 57 studies on sun exposure and melanoma showed that intermittent sun exposures, (e.g., tan-seeking behaviour) and a history of sunburns substantially doubled the melanoma risk [5]. Melanoma susceptibility may also be determined by pigmentary characteristics such as the hair, eye, and skin colour, Fitzpatrick classification of skin sensitivity to sunburns, and ability to tan, together with the number of nevi, family history of MM cancer, and actinic damage indicators [36,37].

Solar ultraviolet radiation is an established cause of melanoma, and sunscreen use is recommended for sun protection in addition to using clothing and staying in the shade. Melanoma may also be preventable by sunscreen use. A recent cohort study observed that during intentional sunbathing, the use of SPF $>15$ sunscreen could reduce the melanoma risk when compared with the use of SPF < 15 sunscreen. Moreover, the use of SPF $>15$ sunscreen by all women aged 40 to 75 years could lead to an $18 \%$ drop in the melanoma incidence in approximately 10 years [38].

\section{Artificial Tanning Devices Use and Skin Cancer}

After the IARC classification on artificial tanning devices as being carcinogenic to humans (based on two meta-analyses on the association between indoor tanning and skin cancer that observed an increasing risk of melanoma, particularly when exposure started at approximately 30 years of age), new epidemiological studies have strengthened the evidence for a causal relationship between indoor tanning and skin cancer. In addition, a positive association between the use of sunbeds and ocular melanoma was observed in several case control studies, also with a greater risk of first exposures at a younger age [39]. Preventive measures such as information on risk or the parents' authorization for young users seem to be ineffective, as pointed out in some studies [39]. Strong actions, like those adopted in Iceland, or the total ban of sunbed use, as in Brazil or Australian states, need to be further assessed [39]. In some countries, a total ban of sunbeds has been applied, and in other countries controls to operators have been implemented. In Italy, legislative controls have been introduced so that sunbed operators are required to prohibit the use of sunbeds by people with fair skin and by pregnant women. In Italy and in other countries in Europe there is a limit at $0.3 \mathrm{~W} / \mathrm{m} 2$, but this limit has been frequently exceeded [40,41].

A recent report from the European Commission's Scientific Committee on Health, Environmental and Emerging Risks and the World Health Organization concluded that a large proportion of melanoma and non-melanoma skin cancer is attributable to the use of sunbeds, and that there is no need to use sunbeds because there are no health benefits and they are not needed to achieve an optimal vitamin $\mathrm{D}$ level. The overall conclusion was that there is no safe limit for UV irradiance from sunbeds [42]. A recent study provided an estimation of the impact in Belgium, demonstrating that promoting UV protective behaviour at the national level, along with the national ban on sunbed use, can led to positive health and economic benefits [43].

\section{Actions for Primary Prevention: The Example of The Australian Campaigns}

Primary prevention can halt the rise of skin cancer and decrease morbidity and mortality. The effectiveness of public health primary care campaigns has been demonstrated in several countries 
through the saving of lives and costs. Australia was the first country that successfully implemented health campaigns with the aim to reduce the skin cancer incidence. In 2010-2014, melanoma was the most commonly diagnosed cancer in young Australians, accounting for $15 \%$ of all cancers diagnosed. But age-standardised incidence rates for melanoma fell from 96 new cases per 1 million young Australians in 1985-1989 to 44 new cases per 1 million in 2010-2014 [44].

SunSmart@is an Australian program with the specific aim of preventing and reducing the skin cancer incidence, morbidity, and mortality through a targeted prevention and early detection program [45]. The programs operate in each state and territory of Australia by respective Cancer Councils. The specific aims of Sun Smart are: "to improve skin cancer prevention awareness, knowledge, attitudes and behaviour in priority populations but also to support priority populations to detect skin cancers earlier and to advocate for measures reducing the health and economic burdens of skin cancer" [45].

\section{Role of Occupational Physicians and General Practitioners}

The role of occupational physicians and general practitioners in the diagnosis and management of skin cancer, but also in informing workers and patients on UVR cancer risk, should be considered. Training for identifying skin cancers may increase the reporting of skin cancers and the improvement of early detection. The impact of short formal training on the diagnostic and referral accuracy of general practitioners in melanoma screening was evaluated in an Italian study; an attendance at 4-formal training sessions was able to increase the specificity of general practitioners as to dermatologists' referral of suspicious lesions, without a significant loss in sensitivity concerning melanoma [46].

Education campaigns to encourage self-examination coupled with a rapid access to specialized dermatological clinics may be considered a key strategy in the realization of the early detection of MM and NMSC. An alternative to an initial visit to the general practitioner's may be the open access to a skin cancer clinic by individual decision. In Italy, it has been observed that, on the occasion of the Italian nation-wide "Skin Cancer Day" campaign promoted by the Federation of Italian Dermatological Societies, open access clinics may increase public awareness regarding skin cancer [47].

\section{Conclusions}

UVR is part of the electromagnetic spectrum emitted from the sun or from artificial sources such as tanning devices. UVR is the main cause of skin cancer, including MM and NMSC. The incidence of skin cancer has increased over recent decades. Skin cancer is the most common cancer in populations characterized as being fair-skinned. Exposure to UVR constitutes a risk for outdoor workers as it causes skin cancer, particularly NMSC, a very common cancer in humans. A strong action is needed to legislate for the recognition of NMSC and AK as an occupational disease. Many outdoor workers employed in different productive sectors, not only the traditional ones (agriculture, fishing, construction, and marble quarrying), are exposed to high levels of UVR, such as workers employed in bathing establishments.

The prevention of adverse health effects on skin, but also on eyes, in outdoor workers exposed to solar UVR needs to be based on various preventive actions, including a physical change in the work environment, the use of personal protective equipment and clothing, but also information and specific training of workers and the adequate health surveillance of exposed workers.

Furthermore, among exposed workers welders must also be considered. The actions of primary prevention must involve occupational physicians and general practitioners, employers and workers, and their safety representatives. Information and training, as well as awareness about this risk, must be implemented (even using new tools, e.g., telephone apps) to ensure that this risk is better known.

Differences in UVR exposure, but also in behaviours, may exist among different outdoor workers; tailoring prevention programs to different types of outdoor work and based on workers' individual needs could be the key to reducing the risk of NMSC.

Additionally, secondary prevention actions must be put in place, such as the surveillance of the pathology and the creation of diagnostic therapeutic pathways for workers affected by these pathologies. 
UVR from sunlight can be reduced but not completely avoided, and complete avoidance is not recommended because of the health benefits of UVR exposure (largely related to vitamin D). Skin cancer is largely preventable when appropriate sun protection measures are taken, such as staying in the shade, wearing sun protective clothing, applying sunscreen and avoiding indoor tanning; furthermore, the early detection of skin cancer decreases its potential morbidity and mortality. Primary prevention aims to reduce the cancer incidence through specific programs that have a proven effectiveness and that are implemented to reduce exposure.

Preventive measures have been proposed to decrease the risk of skin cancer associated with sunbed use, including a total ban. It then seems that strong actions, preferably through regulation, could actually have an impact on the use of sunbeds and later on the incidence of melanoma, especially in countries where the use of this practice is high.

The role of occupational physicians and general practitioners in the diagnosis and management of skin cancer should also be considered.

In conclusion, skin cancer represents the most common type of cancer in the white population worldwide, and its incidence has dramatically increased during the last decades. UVR is believed to be the most important risk factor responsible for this trend. The prominent role of UVR (natural or artificial) renders skin cancer most suitable for primary prevention, because the main risk factor can be avoided or reduced. Public education mass media campaigns are important interventions for influencing behavior modifications. National standardized programs of proven efficacy, such as that implemented in Australia, should also be implemented in other countries, for example in Italy. These programs should to be tailored to the country's specificity, and should specifically should target at-risk characteristics (e.g., age, gender, skin type) but also types of work. These programs also need to be regularly updated.

Funding: This research received no external funding.

Conflicts of Interest: The authors declare no conflict of interest.

\section{References}

1. Lucas, R.M.; McMichael, A.J.; Armstrong, B.K.; Smith, W.T. Estimating the global disease burden due to ultraviolet radiation exposure. Int. J. Epidemiol. 2008, 37, 654-667. [CrossRef] [PubMed]

2. Urbach, F.; Forbes, P.D.; Davies, R.E.; Berger, D. Cutaneous photobiology: Past, present and future. J. Investig. Dermatol. 1976, 67, 209-224. [CrossRef] [PubMed]

3. Armstrong, B.K.; Kricker, A.; English, D.R. Sun exposure and skin cancer. Australas J. Dermatol. 1997, 38 (Suppl. 1), S1-S6. [CrossRef] [PubMed]

4. Armstrong, B.K.; Cust, A.E. Sun exposure and skin cancer, and the puzzle of cutaneous melanoma: A perspective on Fears et al. Mathematical models of age and ultraviolet effects on the incidence of skin cancer among whites in the United States. American Journal of Epidemiology 1977; 105: 420-427. Cancer Epidemiol. 2017, 48, 147-156.

5. Gandini, S.; Sera, F.; Cattaruzza, M.S.; Pasquini, P.; Picconi, O.; Boyle, P.; Melchi, C.F. Meta-analysis of risk factors for cutaneous melanoma: II. Sun exposure. Eur. J. Cancer 2005, 41, 45-60. [CrossRef]

6. International Agency for Research on Cancer; WHO. Solar and Ultraviolet Radiation. In IARC Monographs on the Evaluation of Carcinogenic Risks to Humans; IARC: Lyon, France, 1992; Volume 55. Available online: http://monographs.iarc.fr (accessed on 21 October 2019).

7. International Agency for Research on Cancer; WHO. Radiation. In IARC Monographs on the Evaluation of the Carcinogenic Risk of Chemicals to Humans; IARC: Lyon, France, 2012; Volume 100D. Available online: http://monographs.iarc.fr (accessed on 21 October 2019).

8. Erdmann, F.; Lortet-Tieulent, J.; Schüz, J.; Zeeb, H.; Greinert, R.; Breitbart, E.W.; Bray, F. International trends in the incidence of malignant melanoma 1953-2008-are recent generations at higher or lower risk? Int. J. Cancer 2013, 132, 385-400. [CrossRef]

9. Lomas, A.; Leonardi-Bee, J.; Bath-Hextall, F. A systematic review of worldwide incidence of nonmelanoma skin cancer. Br. J. Dermatol. 2012, 166, 1069-1080. [CrossRef] 
10. Bray, F.; Ferlay, J.; Soerjomataram, I.; Siegel, R.L.; Torre, L.A.; Jemal, A. Global cancer statistics 2018: GLOBOCAN estimates of incidence and mortality worldwide for 36 cancers in 185 countries. CA Cancer J. Clin. 2018, 68, 394-424. [CrossRef]

11. AIOM; AIRTUM. I Numeri del Cancro in Italia 2018; Intermedia Editore: Orvieto, Italy, 2018.

12. Housman, T.S.; Williford, P.M.; Feldman, S.R.; Teuschler, H.V.; Fleischer, A.B., Jr.; Goldman, N.D.; Balkrishnan, R.; Chen, J. Non melanoma skin cancer: An episode of care management approach. Dermatol. Surg. 2003, 29, 700-711.

13. Gordon, L.G.; Rowell, D. Health system costs of skin cancer and cost-effectiveness of skin cancer prevention and screening: A systematic review. Eur. J. Cancer Prev. 2015, 24, 141-149. [CrossRef]

14. Greinert, R.; de Vries, E.; Erdmann, F.; Espina, C.; Auvinen, A.; Kesminiene, A.; Schüz, J. European Code against Cancer 4th Edition: Ultraviolet radiation and cancer. Cancer Epidemiol. 2015, 39 (Suppl. 1), S75-S83. [CrossRef]

15. Mirabelli, D.; Kauppinen, T. Occupational exposures to carcinogens in Italy: An update of CAREX database. Int. J. Occup. Environ. Health 2005, 11, 53-63. [CrossRef]

16. English, D.R.; Armstrong, B.K.; Kricker, A.; Fleming, C. Sunlight and cancer. Cancer Causes Control 1997, 8, 271-283. [CrossRef]

17. Blair, A.; Zahm, S.H. Agricoltural exposures and cancer. Environ. Health Perspect. 1995, 103 (Suppl. 8), 205-208.

18. Naldi, L.; Dilandro, A.; D'Avanzo, B.; Parazzini, F. Host-related and enviroimental risk factors for cutaneous basal cell carcinoma: Evidence from an italian case-control study. J. Am. Acad. Dermatol. 2000, 42, 446-452. [CrossRef]

19. Pukkala, E.; Saarni, H. Cancer incidence among Finnish seafarers, 1967-1992. Cancer Causes Control 1996, 7, 231-239. [CrossRef]

20. Schmitt, J.; Seidler, A.; Diepgen, T.L.; Bauer, A. Occupational ultraviolet light exposure increases the risk for the development of cutaneous squamous cell carcinoma: A systematic review and meta-analysis. Br. J. Dermatol. 2011, 164, 291-307. [CrossRef]

21. Bauer, A.; Diepgen, T.L.; Schmitt, J. Is occupational solar ultraviolet irradiation a relevant risk factor for basal cell carcinoma? A systematic review and meta-analysis of the epidemiological literature. Br. J. Dermatol. 2011, 165, 612-625. [CrossRef]

22. Milon, A.; Bulliard, J.L.; Vuilleumier, L.; Danuser, B.; Vernez, D. Estimating the contribution of occupational solar ultraviolet exposure to skin cancer. Br. J. Dermatol. 2014, 170, 157-164. [CrossRef]

23. Trakatelli, M.; Barkitzi, K.; Apap, C.; Majewski, S.; De Vries, E.; the EPIDERM Group. Skin cancerrisk in outdoor workers: A European multicenter case-control study. J. Eur. Acad. Dermatol. Venereol. 2016, 30 (Suppl. 3), 5-11. [CrossRef]

24. Wong, C.F.; Airey, D.K.; Fleming, R.A. Annual reduction of solar UV exposure to the facial area of outdoor workers in Southeast Queensland by wearing a hat. Photodermatol. Photoimmunol. Photomed. 1996, 12, 131-135. [CrossRef] [PubMed]

25. Thieden, E.; Collins, S.M.; Philipsen, P.A.; Murphy, G.M.; Wulf, H.C. Ultraviolet exposure patterns of Irish and Danish gardeners during work and leisure. Br. J. Dermatol. 2005, 153, 795-801. [CrossRef] [PubMed]

26. Miligi, L.; Benvenuti, A.; Legittimo, P.; Badiali, A.M.; Cacciarini, V.; Chiarugi, A.; Crocetti, E.; Alberghini Maltoni, S.; Pinto, I.; Zipoli, G.; et al. Solar ultraviolet radiation risk in outdoor workers: A specific project of Tuscany Region (Italy). Epidemiol. Prev. 2013, 37, 51-59. [PubMed]

27. International Commission on Non-Ionizing Radiation Protection. Protecting Workers from Ultraviolet Radiation; ICNIRP 14/2007; ICNIRP: Oberschleissheim, Germany, 2007.

28. John, S.M.; Trakatelli, M.; Gehring, R.; Finlay, K.; Fionda, C.; Wittlich, M.; Augustin, M.; Hilpert, G.; Barroso Dias, J.M.; Ulrich, C.; et al. CONSENSUS REPORT: Recognizing non-melanomaskin cancer, including actinic keratosis, as an occupational disease-A Call to Action. J. Eur. Acad. Dermatol. Venereol. 2016, 30 (Suppl. 3), 38-45. [CrossRef]

29. Gobba, F.; Modenese, A.; John, S.M. Skin cancer in outdoor workers exposed to solar radiation: A largely underreported occupational disease in Italy. J. Eur. Acad. Dermatol. Venereol. 2019, 33, 2068-2074. [CrossRef]

30. International Agency for research on cancer; WHO. Welding, Molybdenum Trioxide, and Indium Tin Oxide. In IARC Monographs on the Evaluation of Carcinogenic Risks to Humans; IARC: Lyon, France, 2018; Volume 118. 
31. Falcone, L.M.; Zeidler-Erdely, P.C. Skin cancer and welding. Clin. Exp. Dermatol. 2019, 44, 130-134. [CrossRef]

32. Gandini, S.; Palli, D.; Spadola, G.; Bendinelli, B.; Cocorocchio, E.; Stanganelli, I.; Miligi, L.; Masala, G.; Caini, S. Anti-hypertensive drugs and skin cancer risk: A review of the literature and meta-analysis. Crit. Rev. Oncol. Hematol. 2018, 122, 1-9. [CrossRef]

33. The cancer council Australia's skin cancer committee Victoria. Skin Cancer and Outdoor Workers: A Guide for Employers; The cancer council Victoria: Melbourne, Australia, 2007.

34. Grifoni, D.; Bacci, L.; Zipoli, G.; Carreras, G.; Baronti, S.; Sabatini, F. Laboratory and outdoor assessment of UV protection offered by flax and hemp fabrics dyed with natural dyes. Photochem. Photobiol. 2009, 85, 313-320. [CrossRef]

35. Pont, A.R.; Charron, A.R.; Brand, R.M. Active ingredients in sunscreens act as topical penetration enhancers for the herbicide 2,4-dichlorophenoxyacetic acid. Toxicol. Appl. Pharmacol. 2004, 195, 348-354. [CrossRef]

36. Gandini, S.; Sera, F.; Cattaruzza, M.S.; Pasquini, P.; Zanetti, R.; Masini, C.; Boyle, P.; Melchi, C.F. Meta-analysis of risk factors for cutaneous melanoma: III. Family history, actinic damage and phenotypic factors. Eur. J. Cancer 2005, 41, 2040-2059. [CrossRef]

37. Gandini, S.; Sera, F.; Cattaruzza, M.S.; Pasquini, P.; Abeni, D.; Boyle, P.; Melchi, C.F. Meta-analysis of risk factors for cutaneous melanoma: I. Common and atypical naevi. Eur. J. Cancer 2005, 41, 28-44. [CrossRef] [PubMed]

38. Ghiasvand, R.; Weiderpass, E.; Green, A.C.; Lund, E.; Veierød, M.B. Sunscreen Use and Subsequent Melanoma Risk: A Population-Based Cohort Study. J. Clin. Oncol. 2016, 34, 3976-3983. [CrossRef] [PubMed]

39. Gandini, S.; Doré, J.F.; Autier, P.; Greinert, R.; Boniol, M. Epidemiological evidence of carcinogenicity of sunbed use and of efficacy of preventive measures. J. Eur. Acad. Dermatol. Venereol. 2019, 33 (Suppl. 2), 57-62. [CrossRef] [PubMed]

40. Nilsen, L.T.; Hannevik, M.; Veierød, M.B. Ultraviolet exposure from indoor tanning devices: A systematic review. Br. J. Dermatol. 2016, 174, 730-740. [CrossRef]

41. Facta, S.; Fusette, S.S.; Bonino, A.; Anglesio, L.; d'Amore, G. UV emissions from artificial tanning devices and their compliance with the European technical standard. Health Phys. 2013, 104, 385-393. [CrossRef]

42. Scientific Committee on Health, Environmental and Emerging Risks SCHEER "Opinion on Biological Effects of Ultraviolet Radiation Relevant to Health with Particular Reference to Sunbeds for Cosmetic Purposes". Available online: https://ec.europa.eu/health/sites/health/files/scientific_committees/scheer/docs/scheer_o_ 003.pdf (accessed on 30 October 2019).

43. Pil, L.; Hoorens, I.; Vossaert, K.; Kruse, V.; Tromme, I.; Speybroeck, N.; Brochez, L.; Annemans, L. Burden of skin cancer in Belgium and cost-effectiveness of primary prevention by reducing ultraviolet exposure. Prev. Med. 2016, 93, 177-182. [CrossRef]

44. Welfare AIoHa. Cancer in Adolescents and Young Adults in Australia. 2018. Available online: https://www. aihw.gov.au/reports/cancer/cancer-adolescents-young-adults/contents/summary (accessed on 6 December 2019).

45. Available online: https://www.sunsmart.com.au/ (accessed on 6 December 2019).

46. Carli, P.; De Giorgi, V.; Crocetti, E.; Caldini, L.; Ressel, C.; Giannotti, B. Diagnostic and referral accuracy of family doctors in melanoma screening: Effect of a short formal training. Eur. J. Cancer Prev. 2005, 14, 51-55. [CrossRef]

47. Carli, P.; De Giorgi, V.; Giannotti, B.; Seidenari, S.; Pellacani, G.; Peris, K.; Piccolo, D.; Rubegni, P.; Andreassi, L. Skin cancer day in Italy: Method of referral to open access clinics and tumour prevalence in the examined population. Eur. J. Dermatol. 2003, 13, 76-79.

(C) 2020 by the author. Licensee MDPI, Basel, Switzerland. This article is an open access article distributed under the terms and conditions of the Creative Commons Attribution (CC BY) license (http://creativecommons.org/licenses/by/4.0/). 